\title{
Genius Architect or Clever Thief-How Plasmodiophora brassicae Reprograms Host Development to Establish a Pathogen-Oriented Physiological Sink
}

\author{
Robert Malinowski, ${ }^{\dagger}$ William Truman, and Sara Blicharz \\ Department of Integrative Plant Biology, Institute of Plant Genetics of the Polish Academy of Sciences, ul. Strzeszyńska 34, \\ 60-479 Poznań, Poland
}

Accepted 16 June 2019.

\begin{abstract}
When plants are infected by Plasmodiophora brassicae, their developmental programs are subjected to extensive changes and the resultant clubroot disease is associated with formation of large galls on underground tissue. The pathogen's need to build an efficient feeding site as the disease progresses drives these changes, ensuring successful production of resting spores. This developmental reprogramming is an outcome of interactions between the pathogen and the infected host. During disease progression, we can observe alteration of growth regulator dynamics, patterns of cell proliferation and differentiation, increased cell expansion, and eventual cell wall degradation as well as the redirection of nutrients toward the pathogen. Recently, detailed studies of anatomical changes occurring during infection and studies profiling transcriptional responses have come together to provide a clearer understanding of the sequence of events and processes underlying clubroot disease. Additionally, genome sequencing projects have revealed $P$. brassicae's potential for the production of signaling molecules and effectors as well as its requirements and capacities with respect to taking up host nutrients. Integration of these new findings together with physiological studies can significantly advance our understanding of how $P$. brassicae brings about reprogramming of host development. This article summarizes the current state of knowledge on cellular changes induced by $P$. brassicae infection and aims to explain their impact and importance for both the host and the pathogen.
\end{abstract}

Keywords: clubroot, gall development, gall-forming pathogen, microscopy and imaging, Plasmodiophora brassicae, protist-plant interactions

${ }^{\dagger}$ Corresponding author: R. Malinowski; rmal@igr.poznan.pl

Funding: R. Malinowski, W. Truman, and S. Blicharz are supported by the European Union's Seventh Framework Programme for research, technological development, and demonstration under FP7 Coordination of NonCommunity Research Programmes grant agreement number 621321 and Polish financial sources for education in the years 2015 to 2019 allocated to an international co-financed project. R. Malinowski is the BIO-TALENT ERA-CHAIR team leader. R. Malinowski was also supported by the National Science Centre Poland (Narodowe Centrum Nauki) SONATA BIS2 grant number 2012/07/E/NZ3/00510, "Integrated approach for deciphering the mechanism leading to shift in cell proliferation/differentiation balance accompanying clubroot infection".

The author(s) declare no conflict of interest.

๑ 2019 The American Phytopathological Society
Plasmodiophora brassicae is a biotrophic protist plant pathogen infecting, mainly, members of the Brassicaceae family (Ludwig-Müller et al. 1999). Its life cycle is governed by the soil and water environments it occupies. Resting spores can survive in the soil for many years, germinating only when optimal conditions for infection occur. The first stage of infection is by haploid zoospores encysting on root hairs of the host plant. Inside infected root hairs, multinucleate primary plasmodia form and develop into zoosporangia which release zoospores back into the soil to act as a source for secondary infection. Secondary zoospores invade the roots of plants and develop into motile secondary plasmodia which are responsible for further expansion and establishment of the disease within the plant (Kageyama and Asano 2009). Early stages of secondary infection are accompanied by massive changes in host metabolism which sets up a new, pathogen-oriented, physiological sink (Devos et al. 2006). This results in hyperplasia followed by hypertrophy of the underground parts of the plant and the development of galls (Malinowski et al. 2012). Macroscopically, this can be observed as a major root and hypocotyl deformation, hence the disease name: clubroot. The resulting structures secure space for pathogen multiplication and act as a perfectly tailored feeding site. The significance of galls as a specialized feeding site has been illustrated by detailed studies on $P$. brassicaedriven alterations of host sugar metabolism (Evans and Scholes 1995; Keen and Williams 1969) as well as anatomical changes facilitating acquisition of plant assimilate by the pathogen (Malinowski et al. 2012). Gall architecture changes during disease progression in response to pathogen needs. Initially, they support colonization of large numbers of cells and, subsequently, they act as a new, competing physiological sink fulfilling the nutritional requirements for spore maturation. Once spores mature, the disintegration of underground plant parts occurs and spores are released to the soil. As we see, completion of the entire life cycle of the pathogen is accompanied by complex rearrangements of the host. Here, we would like to present recent progress in understanding host cellular changes driven by $P$. brassicae infection and explain the ways in which particular features of gall architecture facilitate successful biotrophy.

\section{MERISTEMATIC ACTIVITY CHANGES AND THEIR IMPLICATIONS FOR PLANT ANATOMY}

Plants acquire their final form and maintain the functions of particular organs through the action of local sites of meristematic activity (Jürgens 2003). The apical-basal axis is formed through the action of the primary root and shoot meristems. 
During later stages of plant development, as a consequence of local proliferative activity within the pericycle, lateral root meristems emerge. In the upper parts of plants, auxiliary meristems are formed and their action determines shoot branching. Radial secondary growth of plant organs is regulated by vascular cambium and phellogen activity coordinated by phytohormones. It is known that $P$. brassicae infection affects the levels of growth regulators which control meristematic activity (Ludwig-Müller et al. 2009; Schuller et al. 2014). Much effort has been directed toward dissecting the role of phytohormones in clubroot disease but a clear picture has yet to fully emerge. Recent works show that, depending on the genotype, different patterns of hormonal changes were found to correlate with the capacity of the host to trigger defense responses against P. brassicae infection (Lemarié et al. 2015; Prerostova et al. 2018). Downstream cellular changes triggered by $P$. brassicae in roots and hypocotyls seem to be more conserved. The first indications of changes in meristematic activity can be observed in the underground parts of plants as early as 4 days postinfection (dpi) as an increase in proliferation in the cortex of infected roots and hypocotyls (Devos et al. 2006). At this stage (18 days after germination), infection also enhanced local cell cycle activity within the pericycle, at the sites of lateral root meristems. The process of lateral root formation is, to a large extent, regulated by auxins (Casimiro et al. 2001), which are also known to mediate host responses to $P$. brassicae infection (Jahn et al. 2013). Plants respond to $P$. brassicae infection with increased levels of the TIR1 auxin receptor as well as Gretchen Hagen 3 (GH3) auxin conjugate synthases involved in controlling the homeostasis of auxin levels; the expression of downstream responses mediated by auxin response factors is also upregulated.

As the disease progresses, an intensification of existing meristematic activities in the vascular cambium occurs. In Arabidopsis clubroot gall development, a clear distinction can be made between the proliferative stage of gall formation related to cambial cell divisions and the later expansive phase, which involves organ hyperplasia and formation of enlarged cells (Fig. 1). Whereas in noninfected plants the progeny of cells in the cambial meristems advance toward differentiation, in $P$. brassicae-infected hypocotyls, they remain trapped in the mitotic state (Olszak et al. 2019). Suppression of cambial cell differentiation occurs at the late G2/M cell cycle progression checkpoint and is at least partially mediated by the dimerization partner DP, retinoblastoma RB-like, E2F, and MuvB (DREAM) regulatory complex (Olszak et al. 2019). In particular, transcript levels of $M Y B 3 R 1$ and $M Y B 3 R 4$ as well as E2Fa transcription factors, known to be responsible for activation of G2/Mspecific genes, were elevated during the proliferative phase of gall development ( 7 to $18 \mathrm{dpi}$ ) in Arabidopsis. This was also accompanied by increased expression of DREAM targets, whose promoters contain the MSA motif such as B-type cyclin genes and cyclin-dependent kinases (Fig. 1). Once the production of resting spores starts, intense proliferation of host cambial cell progeny is no longer observed; instead, localized cell enlargement becomes the dominant pattern (Fig. 1). Thus far, it is not known which factors are directly involved in this switching of the root and hypocotyl cell fate programs. However, it has been shown that resting spore development is accompanied by host responses facilitating cell expansion, in particular those related to auxin, cytokinin, and brassinosteroid (BR) metabolism (Schuller et al. 2014). During this expansive stage of gall development, manipulation of host cell cycle control shifts to stimulate endoreduplication (Olszak et al. 2019). Endocycling accompanies organ growth and is essential for ploidydriven cell size increase (De Veylder et al. 2011). For other biotrophic plant-microbe interactions, endoreduplication has been shown to be an important element facilitating the enhancement of metabolic activity in host cells (Chandran et al. 2010). The importance of host endoreduplication in the formation of large, spore-filled cells likely rises from both its potentiation of increased cell volume to provide space for more spores and its impact on boosting cellular metabolism to provide nutrients for their multiplication and maturation.

The pathogen-driven modification of host meristematic activities also profoundly affects vascular tissue development, resulting in a dramatic repatterning. Both phloem and xylem development are affected; most likely, however, as a consequence of activation of two separate signaling cascades. Surprisingly though, $P$. brassicae does not influence the canonical CLE41/44-PXY-WOX4 cambium proliferation or differentiation regulatory pathway responsible for the balance between phloem and xylem development. Mutation of the WOX4 gene does not limit $P$. brassicae-driven cambium proliferation and transcript levels of PXY,CLE41,CLE44, and WOX4 genes are unaltered during the proliferative stage of gall formation (Malinowski et al. 2012). Expression patterns of the host genes regulating xylem differentiation observed during $P$. brassicae infection show that the xylogenesis process is already affected at an early signaling stage (Malinowski et al. 2012). In developing galls, the expression of two key transcription factors stimulating commitment of cell fate to xylogenesis decreases: VND7 involved in the establishment of protoxylem and VND6 involved in metaxylem differentiation (Malinowski et al. 2012). Downregulation of MYB46 indicates that the machinery of secondary cell-wall synthesis necessary for xylogenesis is also suppressed. The final step of xylem formation, achieved through programmed cell death, is also restricted by downregulation of the cysteine protease genes $X C P 1$ and $X C P 2$. It is possible that some clubroot-driven xylem restriction may be dictated by altered miRNA dynamics. It has been shown in cabbage that $P$. brassicae infection leads to an increase in miR156 abundance (Verma et al. 2014) and miR156 is an important element in the network regulating juvenile-toadult phase transition, a process that is accompanied by hypocotyl xylem expansion (Ragni et al. 2011). Despite the fact that disruption of xylogenesis by $P$. brassicae has been widely reported and is a characteristic symptom of clubroot disease linked to plant wilting, we do not know if the signal triggering this response comes from the pathogen or is a consequence of host phytohormone homeostasis destabilization. Because $P$. brassicae infection also arrests xylogenesis in a quadruple cytokinin biosynthesis mutant ipt $1 ; 3 ; 5 ; 7$ incapable of accumulating cytokinin, the first hypothesis seems to be more plausible (Malinowski et al. 2016). Xylogenesis is under the control of networks regulating the balance between cell proliferation and endoreduplication (Taylor-Teeples et al. 2015); disruption of this balance in myb3r4 mutants and $E 2 F a$-silenced plants did not rescue the xylogenesis process (Olszak et al. 2019). The release of multiple genome sequences for $P$. brassicae in recent years has stimulated the hunt for pathogen effector proteins responsible for manipulating host processes (Pérez-López et al. 2018). The identification of effectors responsible for directly influencing xylogenesis would be of great interest because such a discovery could lead to strategies for mitigating the water distribution problems arising from infection which have such a critical impact on crop yield.

The altered balance between proliferation and differentiation observed in hypocotyls of $P$. brassicae-infected plants also influences the meristematic activity within phloem bundles. Altered phloem anatomy was first reported by Gustafsson et al. (1986), who pointed out that sieve cells dominate over tracheids in developing galls. Further characterization of phloem tissue in $P$. brassicae-infected hypocotyls, using the phloem-specific marker CLE44 fused to the $\beta$-glucuronidase $(G U S)$ reporter 
gene, showed that disease does not change the number of phloem bundles but increases their cellular complexity (Malinowski et al. 2012). More detailed observations performed using electron microscopy showed that the number of all phloem cell types (companion cells [CC], phloem parenchyma, and sieve elements [SE]) within the bundle increased proportionally (Walerowski et al. 2018). This is consistent with the increased expression of numerous genes involved in early steps of phloem differentiation that accompanies gall development (Walerowski et al. 2018). Some of these critical regulators such as $B R X, C V P 2$, and $O P S$ act early in phloem fate acquisition and the very earliest steps of SE formation. Analysis of ops-2 and brx-2 loss-of-function mutants and the cvp2-1 cvl1-1 double mutant which exhibit different degrees of phloem anatomy disruption has confirmed the involvement of these genes in the pathogen-driven reprogramming of phloem bundle complexity within galls. Infected plants carrying mutations in these phloem differentiation genes are much more severely affected by $P$. brassicae infection and die significantly earlier than wild-type plants. The life cycle of $P$. brassicae is accelerated in these mutants, with earlier formation of resting spores. Knowing that phloem can act as a conduit for both signaling and nutritional compounds, we can assume that this vascular reprogramming is a crucial element in fine tuning the biotic interaction between the host and pathogen. Because $P$. brassicae infection leads to increases in proliferation of phloem lineage cells, including phloem CC that are known to be involved in sugar loading and unloading (Slewinski et al. 2013), we propose that the importance of these changes to host vascular architecture will be to increase the availability of the host soluble sugars and that this availability will govern $P$. brassicae's switch from multiplication to maturation.

\section{THE GALL AS A SITE OF INTENSE CARBOHYDRATE CONSUMPTION}

Sequencing of $P$. brassicae has revealed that, to a large extent, the pathogen relies on external sources of carbohydrates (Rolfe et al. 2016; Schwelm et al. 2015). To fulfill its requirements, $P$. brassicae triggers redirection of assimilate in infected host plants. In ${ }^{14} \mathrm{CO}_{2}$ pulse-feeding experiments, Keen and Williams (1969) found that increased levels of highly radioactive sucrose but not hexoses were present in clubroot galls. Sucrose translocation stimulated by clubroot disease was also reported by Evans and Scholes (1995), who found that sucrose accumulation in leaves decreases upon $P$. brassicae infection. Both studies show that sucrose is the major sugar translocated from source to sink tissues as the disease progresses. Assimilate redirection toward developing galls can be achieved either at source sites via changes in soluble-sugar conversion and phloem loading or at the level of the sink by increased unloading. Also, phloem transport load can be stimulated. In Arabidopsis, sucrose is mainly loaded via active transport from the apoplast. Thus far, no studies describing the exact molecular mechanism of sugar loading in the source organs of $P$. brassicae-infected plants have been published. Irani et al. (2018) reported decreased levels of transcripts involved in photosynthesis as well as carbohydrate transporters in the upper parts of $P$. brassicae-infected plants. At the same time, root systems responded with upregulation of the Calvin cycle, tricarboxylic acid (TCA) cycle, and genes implicated in carbohydrate transport or unloading. The unbalance between responses observed in source and sink tissues suggests that the host may attempt to limit assimilate hijacking by the pathogen by constricting the source. Limiting of sugar availability by decreasing transcription of genes involved in the light phase of photosynthesis and Calvin cycle in Arabidopsis leaves was also observed by Jubault et al. (2013). Concomitantly, starch biosynthesis genes were repressed, whereas those involved in starch degradation were induced. Despite the fact that infected plants limit their primary metabolism in source organs, the pathogen finds ways to relocate carbohydrates toward the sink they create as their feeding site. Increased metabolism of carbohydrates in the sink organs after infection was widely reported (Evans and Scholes 1995; Siemens et al. 2011). $P$. brassicae establishes a very strong carbohydrate sink by local stimulation of host extracellular cell wall invertases (cwINV) (Roitsch and Ehneß 2000). Recently completed

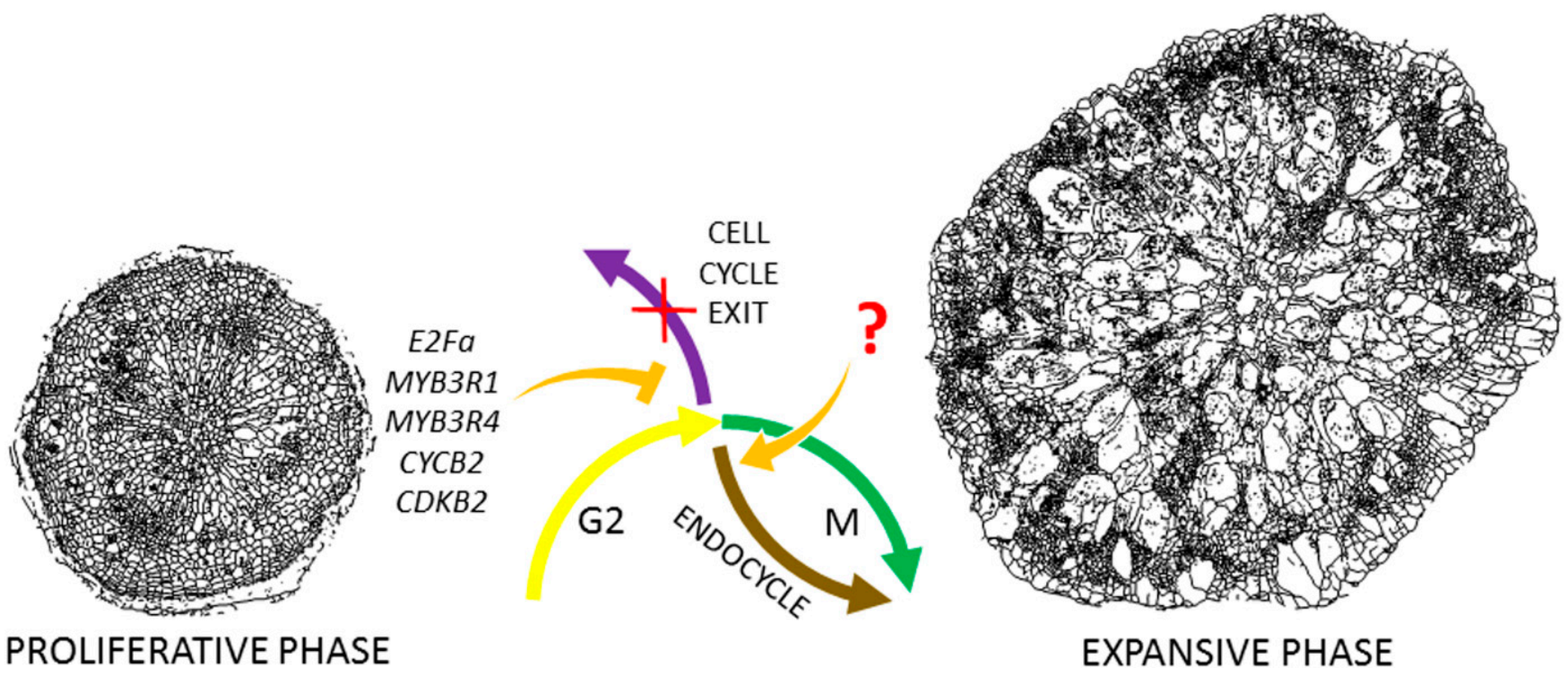

Fig. 1. Plasmodiophora brassicae infection changes meristematic cell fate by manipulation of the G2/M checkpoint. As a consequence of infection, existing host meristematic activity is maintained via the activation of dimerization partner DP, retinoblastoma RB-like, E2F, and MuvB (DREAM) complex members $M Y B 3 R 1, M Y B 3 R 4, E 2 F a$, and their downstream targets, including B-type cyclins and cyclin-dependent kinases. Increased accumulation of these factors marks the proliferative phase of gall formation, in which stimulated cambial activity contributes to root and hypocotyl hyperplasia. As the disease progresses, unknown factors redirect cell fate at the G2/M checkpoint toward cell cycle exit and the endoreduplication process; this contributes to cell enlargement and the organ hypertrophy observed during the expansive phase of gall development. 
$P$. brassicae genome sequencing shows that the pathogen itself does not possess extracellular invertase genes (Rolfe et al. 2016; Schwelm et al. 2015). In this light, we can speculate that the pathogen uptakes sugars in the forms delivered by the host. Upregulation of host sucrose invertases seems to be the most likely way for the availability of host sugar to be increased. Disruption of cwINV activity in galls permitted increased plant tolerance to $P$. brassicae (Siemens et al. 2011). A possible role of cwINV is to facilitate the uptake of apoplastic sucrose unloaded from the phloem tissue by metabolizing it to hexose. Roitsch and Ehneß (2000) as well as Walters and McRoberts (2006) suggested that cwINV activity can be an essential component of cytokinin-dependent carbohydrate sink formation. One possible scenario is that local increases in cytokinin levels induce extracellular invertase activity, influencing in this way sugar unloading and partitioning within the plant. If this is the case for clubroot disease, then increases in cytokinin levels should accompany the later stages of disease development. However, recent work by Malinowski et al. (2016) shows that the main forms of cytokinin do not increase during that time. We cannot exclude the possibility that $P$. brassicae itself can synthesize sufficient cytokinin to trigger extracellular invertase activity. In fact, at least two genes encoding isopentenyl transferases have been identified in the $P$. brassicae genome (Rolfe et al. 2016). In this light, it may be that pathogen-derived cytokinin can trigger assimilate redirection. It is notable, however, that $P$. brassicae spore development is delayed or even arrested in infected quadruple ipt 1;3;5;7 mutants (Malinowski et al. 2016). This suggests that the pathogen-derived pool of cytokinin is probably not sufficient to maintain proper sugar distribution for the pathogen's needs.

Competition between ordinary host sink organs and the pathogen-induced gall is further enhanced by the manipulation of host sugar transporter expression. Carbohydrates redirected by the pathogen are unloaded through the sucrose transporter (SUT) and sugars will eventually be exported transporter (SWEET) proteins. Expression of the host genes encoding these proteins is activated by the pathogen during the secondary phase of the infection, when cell enlargement follows cell proliferation (Malinowski et al. 2012; Walerowski et al. 2018). The upregulation of SUC2/SUC1 and SWEET11/12 is focused around the areas of phloem expansion in the gall, suggesting their involvement in unloading carbohydrate for the pathogen. Increased expression of SUC2/SUT1 was observed at 16 and $26 \mathrm{dpi}$. However, further localization with promoter fusions showed similar patterns between hypocotyls of infected and noninfected plants at $16 \mathrm{dpi}$ whereas, at $26 \mathrm{dpi}$, SUC2/SUT1 signals disappeared in healthy hypocotyls (P. Walerowski and R. Malinowski, unpublished data). This suggests a possible connection of transporter expression with the late stages of gall development when there is a maximum carbohydrate requirement for resting spore formation (Fig. 2). Expression of two other sugar transporters, SWEET11 and -12, was found to increase in hypocotyls of infected plants at 16 and 26 dpi. Consistent with this observation, mutations in SWEET11 and -12 , singly ( $\mathrm{Li}$ et al. 2018) or in combination (Walerowski et al. 2018), slowed disease progression. In addition, Fouriertransform infrared microspectroscopy imaging has revealed the differences in carbohydrate distribution between galls of wild-type Arabidopsis and sweet 11;12 double mutants (Walerowski et al. 2018). Other host transporters possibly involved in increasing the supply of carbohydrates to $P$. brassicae are monosaccharide $/ \mathrm{H}^{+}$symporters of the sugar transporter protein family. Their increased abundance in galls was observed in Arabidopsis (Walerowski et al. 2018) and Brassica oleracea (Zhang et al. 2019); however, these observations have not yet been elaborated with functional studies. P. brassicae also carries its own factors involved in sugar uptake that were found to be differentially expressed over the course of disease progression (Rolfe et al. 2016). Its genome contains SWEET permeases and monosaccharide transporters as well as other transporters that belong to unique classes. It also has endogenous mechanisms for carbohydrate metabolism (glycolysis and TCA cycle); however, better understanding of the involvement of these factors in particular steps of carbohydrate acquisition will require further functional analysis.

Another compound involved in reorientation of the carbohydrate sink during clubroot disease progression is trehalose. Brodmann et al. (2002) reported that plants infected by $P$. brassicae accumulate large amounts of this sugar. They also found that trehalose may, in fact, be synthesized by trehalose-6phosphate synthase encoded by the P. brassicae gene PbTPS1. Trehalose-6-phosphate, which is an intermediate molecule of the trehalose synthesis pathway, regulates sucrose production in source organs and sucrose consumption in sink organs. It has also been shown to be involved in sucrose mobilization from starch during the night (Figueroa and Lunn 2016). Utilization of host substrates for trehalose synthesis could be an important mechanism facilitating the formation of a carbohydrate sink in developing galls. Apparently, infected plants try to cope with this metabolic destabilization either by induction of trehalase activity (Brodmann et al. 2002) or by adapting to tolerate high levels of this metabolite (Gravot et al. 2011). During late stages of gall development, when resting spores are formed, pathogen manipulation of carbohydrate metabolism may be important for maintenance of cell osmotic properties as well as for conversion of soluble sugars to starch when their levels become toxic.

\section{CELLULAR ENVIRONMENT AND CELL INTEGRITY WITHIN THE GALL}

As the disease progresses, cellular integrity in the gall is subjected to counteracting trends toward cell-wall reinforcement and cell-wall loosening as the developmental programs and needs of the host are subverted by the pathogen (Fig. 3). Gall development is also accompanied by cell-wall lesions or cell adhesion changes. In order to maintain its physiological functions, the host needs to counteract these changes. The cell wall is an essential cell component in determining cell fate; its physical and chemical properties influence cell expansion and the direction of cell growth as well as several aspects of differentiation into functional tissues (Thompson 2005; Wojtaszek 2000). Cell walls can be divided into those of primary and secondary type. Primary walls consist mainly of cellulose, hemicellulose, and pectins; they need to withstand mechanical force from turgor pressure and, thus, both their rigidity and extensibility require precise regulation. Secondary cell walls are additionally enriched with lignins and their synthesis usually occurs during cell growth arrest and while mechanical support or a physical barrier is needed. Schuller et al. (2014) showed that, to large extent, cell enlargement within developing galls is regulated by BR. Hypertrophied cell formation in galls is accompanied by increased transcription of genes regulating the BR biosynthesis pathway or encoding positive regulators of BR signaling. Their work also showed that BR mutants exhibit at least partially impaired resting spore formation or maturation. One possible scenario is that the pathogen hijacks the BR signaling pathway to modify the activity or abundance of cell-wall-loosening factors such as expansins (EXP) or xyloglucan endotransglucosylase hydrolases (XTH). It has also been shown that an increase in the xyloglucan endotransglycosylase activity of XTH proteins accompanies the early stages of P. brassicae infection (Devos et al. 2006) and may be related to an increase in epidermal root cell elongation processes observed 
after $P$. brassicae infection. Other reports point out the primary cell wall extensibility modification by EXP as an important mechanism necessary for plant invasion by this pathogen and for subsequent gall formation (Jubault et al. 2013). BR may also regulate cell integrity within galls via the activation of pectin methylesterases (PME). Wolf et al. (2012) showed that a mutation in the BRII gene encoding the BR receptor can influence the increase of pectin esterification caused by PME gene overexpression. Increased PME levels were observed during the early stages of $P$. brassicae infection (Devos et al. 2006); this hyperesterification of pectins may lead to a reduction in cell integrity. Roots infected by $P$. brassicae are fragile and break apart easily and their morphology exhibits a high degree of waving; both of these phenotypes are typical for plants with elevated PME activity. Cell-wall degradation observed during resting spore release can also depend on BR signaling and changes in pectins; however, possible involvement of cellulose-digesting enzymes in this process has also been proposed (Donald et al. 2008). Cell-wall deterioration can be observed even during the early stages of infection and may be related to movement of the pathogen (Devos et al. 2006). PME activity may also contribute to this process. We cannot exclude the possibility that the pathogen produces enzymes or other factors directly or indirectly targeting cell walls in the host. However, this aspect awaits further studies.

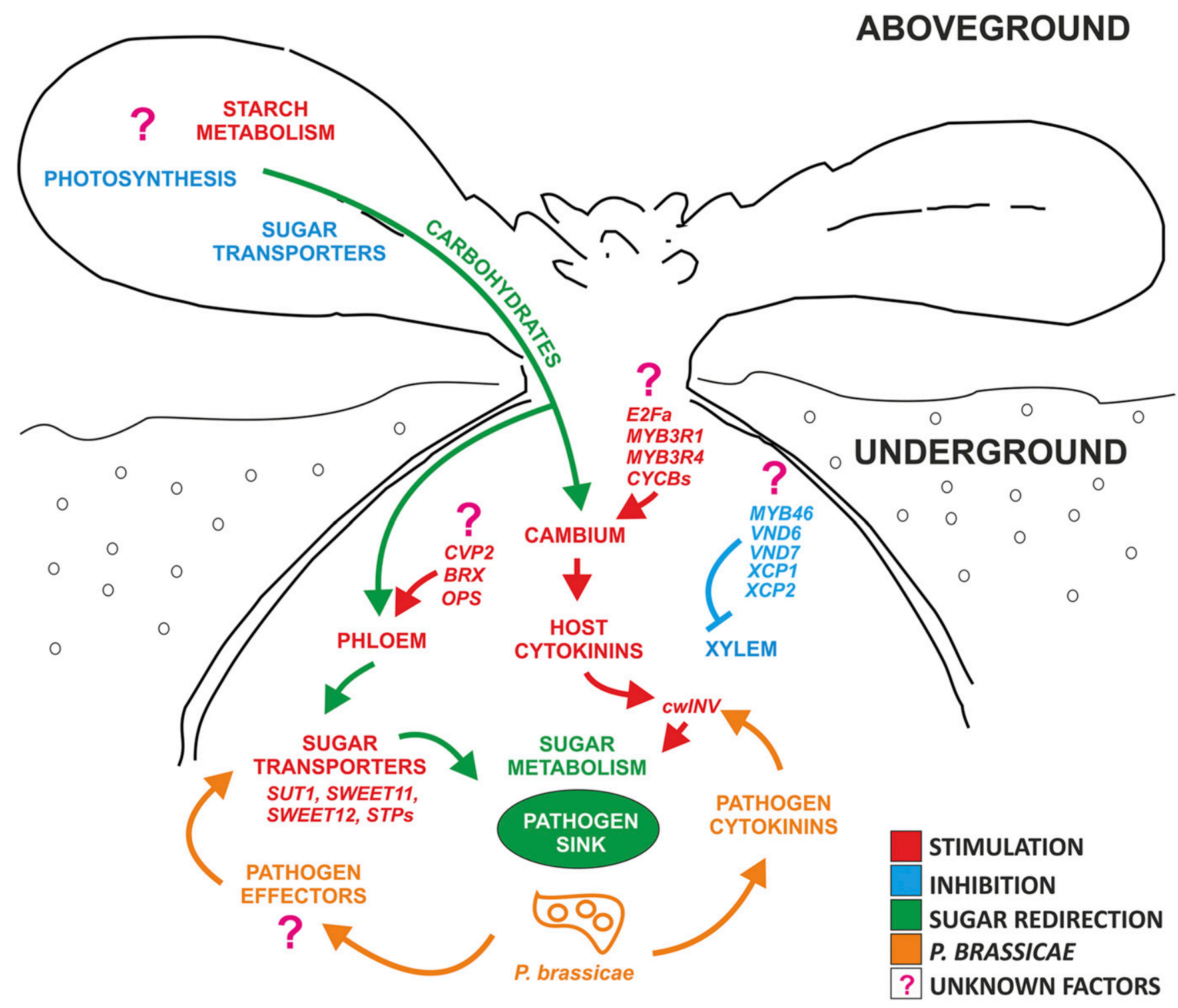

Fig. 2. Interplay between cellular reprogramming and carbohydrate redirection toward the pathogen. Plasmodiophora brassicae infection destabilizes major developmental programs within the whole plant. To cope with the disease, the plant reduces photosynthetic activity as well as sucrose loading. However, the pathogen is able to set up a very strong, competitive carbohydrate physiological sink through the induction of cell wall invertase activity. In response to the high sugar demand, starch metabolism in leaves is stimulated. Diverted sugars may play an important role in stimulating cambial activity and, together with cytokinins (host or pathogen derived), maintain meristematic cells in the mitotic state. Dimerization partner DP, retinoblastoma RB-like, E2F, and MuvB (DREAM) complex members $M Y B 3 R 1, M Y B 3 R 4$, and $E 2 F a$ and their downstream targets such as B-type cyclins sustain cambial mitosis but their precise interaction with sugars and cytokinins is not known. The potential for sugar transport is enhanced by increased phloem complexity in galls but the factors initiating changes in molecular regulatory networks inhibiting xylem or stimulating phloem development are unknown. Sugars diverted toward the underground parts of the plant are consumed by the pathogen; the localized activity of sucrose transporter (SUT), sugars will eventually be exported transporter (SWEET), and sugar transporter protein (STP) factors facilitate this process. Gaps in the emerging model of physiological and developmental reprogramming are labeled with question marks. Pathogen-driven stimulation of processes is shown in red and downregulation in blue. Green represents the redirection of carbohydrate. Data concerning the involvement of particular $P$. brassicae-derived factors in reprogramming are scarce; their presumed action is shown in orange. 
Another important aspect of the cellular environment that merits attention concerns the strategies that the pathogen has developed to cope with and subvert host defense responses. An important issue during establishment of the feeding site is the suppression of host immune mechanisms. At present, intense work aimed at characterization of potential P. brassicaesecreted molecules involved in modification of host responses is being carried out (Pérez-López et al. 2018). Thus far, the most well-characterized factor is PbBSMT, a secreted methyl transferase whose activity is related to suppression of salicylic acid (SA)-related defense signaling (Ludwig-Müller et al. 2015). Recently, using a chemically inducible system Bulman et al. (2019) has shown that increased PbBSMT levels correlated with higher clubroot susceptibility in the host. The authors propose that $P$. brassicae methylates SA, decreasing pools of free SA involved in host in defense signaling. Other such mechanisms deployed by $P$. brassicae to create a favorable environment for gall formation and multiplication remain to be discovered.

In addition to evading and suppressing host defense responses, the pathogen within the developing gall will seek to manipulate metabolic pathways within occupied host cells. A consequence of the pathogen's success in establishing a strong physiological sink is the influx of metabolites, which must be marshalled for optimal spore formation. Recently completed sequencing projects have shown how the $P$. brassicae genome has evolved to cope with this situation (Rolfe et al. 2016; Schwelm et al. 2015); genes encoding factors involved in carbohydrate and lipid metabolism or transport have been identified and their potential roles proposed. One key aspect emerging from these genome analyses is that $P$. brassicae has limited capacity for direct modulation of nitrogen uptake and metabolism. There is a possibility that the pathogen trehalose-6-phosphate synthase gene (PbTPS1), in addition to its role in sugar deposition, may also be important for the proper orchestration of carbohydrate and nitrogen levels in the host. Such a scenario has previously been observed in the rice blast fungus Magnaporthe oryzae (Fernandez and Wilson 2011).

The metabolic sink induced by $P$. brassicae is so strong that accumulation of certain molecules can become toxic; therefore, efficient mechanisms for cellular compartmentation or sequestration have to be deployed. Toxic levels of carbohydrates accumulating within gall cells are sequestered as starch granules; the pathogen can also act to neutralize toxic build ups of fatty acids (Fig. 3A). Bi et al. (2016) have shown that fatty acids are neutralized via esterification and subsequent sequestration in the form of neutral lipids (mainly arachidonic acid) in socalled "lipid droplets". Similarly to Rolfe et al. (2016), they observed that synthesis of fatty acids in plasmodia is accompanied by increased expression of several $P$. brassicae lipaseencoding genes, and subsequent resting spore formation

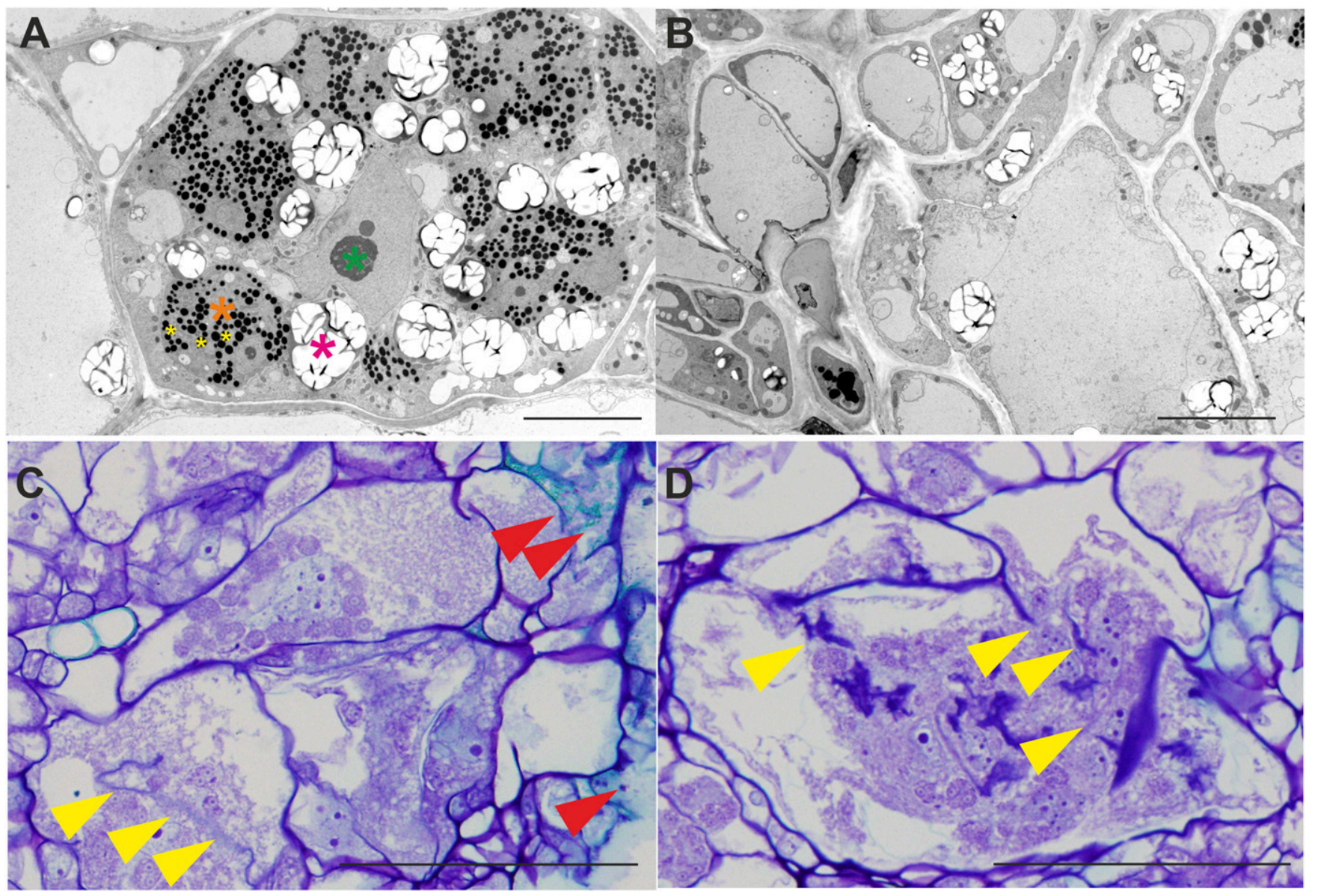

Fig. 3. Serious cellular rearrangements within the gall during late stages of clubroot disease. A, Scanning electron microscopy (SEM) showing the characteristic phenotype of an enlarged cell colonized by the pathogen. Stars represent the following: green $=$ host cell nuclei, magenta $=$ starch grains accumulating in response to high levels of carbohydrates, and orange = Plasmodiophora brassicae plasmodium containing lipid droplets (marked with yellow stars). B, Typical cell-wall deformations of host cells within galls (26 days postinfection [dpi]) observed with SEM. C and D, Toluidine-blue-stained, Technovit-embedded sections of a gall at 32 dpi showing cell wall decay (indicated with yellow arrowheads) and lignification (turquoise cells marked with red arrowheads). Scale bars represent $10 \mu \mathrm{m}(\mathrm{A}$ and $\mathrm{B})$ and $100 \mu \mathrm{m}(\mathrm{C}$ and $\mathrm{D})$. 
coincides with expression of numerous factors involved in lipid metabolism. Integrative analysis of isolated lipid droplets present at different stages of $P$. brassicae development have shown that their role goes far beyond the maintenance of proper cellular environment. These particles can also act as reservoirs that can be accessed when there is a critical cellular requirement for energy, cell membrane synthesis, or production of signaling molecules (Bi et al. 2016).

Metabolic and cellular changes within the developing gall are also tightly connected to auxins, which have been shown to accumulate in large quantities during late stages of disease, facilitating nutrient availability for developing resting spores (Ludwig-Muller 1993). It is known that $P$. brassicae can influence auxin metabolism by induction of host nitrilase genes, which modulate levels of free indole-3-acetic acid (GrsicRausch et al. 2000). Schwelm et al. (2015) reported that the $P$. brassicae genome contains a $P b G H 3$ gene that can regulate auxin homeostasis. The involvement of GH3 factors in developmental reprograming may be part of a conserved signaling network exploited by pathogens for feeding-site formation. It has been shown that $\mathrm{GH} 3$ accumulation accompanies the early phases of symbiotic interactions between Sinorhizobium meliloti and Medicago truncatula (Yang et al. 2015). Because elevated host GH3 transcript levels were observed in hypertrophied cells colonized by P. brassicae (Schuller et al. 2014), it could be that they also act to modify the pathogen-driven auxin increase necessary for cell wall expansion. Due to the fact that auxin is involved in every single aspect of plant life, it is very difficult to dissect how a particular change affects gall formation and function; thus, more studies integrating the interplay with other growth regulators (particularly cytokinins) need to be performed to make a proper appraisal.

\section{CONCLUDING REMARKS}

Important progress has been achieved in understanding the cellular changes leading to gall formation and how this structure fulfils the needs of the pathogen. $P$. brassicae stimulates mitotic activity in the meristematic regions of roots and hypocotyls to increase the number of cells available to be colonized. Detailed understanding of this reprogramming at the cellular and molecular levels may help to develop strategies to reduce the negative impacts of $P$. brassicae infection on crop yield. The gall is also engineered to be a major carbohydrate sink, competing with other host sink organs such as young leaves or developing seed. A future challenge will be to identify and characterize the pathogen factors stimulating the host machinery that is used to establish a new metabolic sink and to siphon off carbohydrates.

Despite various attempts aimed at characterization of the phytohormonal response to infection and how this is manipulated by the pathogen our understanding of this aspect is, as yet, incomplete. This is largely due to the fact that phytohormonal imbalances were frequently studied in isolation whereas more integrative studies, taking into account hormonal cross-talks, are required.

Another level of complexity that should be explored while studying nutrient redirection during clubroot disease is the possible involvement of pathogen-derived agents capable of influencing metabolism and transport. Apart from pathogendriven host metabolic reprogramming, further characterization of $P$. brassicae secreted molecules capable of suppressing host defense machinery may also bring new useful information that helps us to understand the disease progression. In our opinion, future development of an efficient method to modify the $P$. brassicae genome as well as exploration of the genomic diversity between particular pathotypes may open up new avenues for the functional studies of the biological basis of clubroot disease progression.

\section{ACKNOWLEDGMENTS}

We thank M. Sobczak (Warsaw University of Life sciences) for the scanning electron microscopy imaging of galls.

\section{LITERATURE CITED}

Bi, K., He, Z., Gao, Z., Zhao, Y., Fu, Y., Cheng, J., Xie, J., Jiang, D., and Chen, T. 2016. Integrated omics study of lipid droplets from Plasmodiophora brassicae. Sci. Rep. 6: Article 36965.

Brodmann, A., Schuller, A., Ludwig-Müller, J., Aeschbacher, R. A., Wiemken, A., Boller, T., and Wingler, A. 2002. Induction of trehalase in Arabidopsis plants infected with the trehalose-producing pathogen Plasmodiophora brassicae. Mol. Plant-Microbe Interact. 15:693-700.

Bulman, S., Richter, F., Marschollek, S., Benade, F., Jülke, S., and LudwigMüller, J. 2019. Arabidopsis thaliana expressing PbBSMT, a gene encoding a SABATH-type methyltransferase from the plant pathogenic protist Plasmodiophora brassicae, show leaf chlorosis and altered host susceptibility. Plant Biol. (Berlin Ger.) 21:120-130.

Casimiro, I., Marchant, A., Bhalerao, R. P., Beeckman, T., Dhooge, S., Swarup, R., Graham, N., Inzé, D., Sandberg, G., Casero, P. J., and Bennett, M. 2001. Auxin transport promotes Arabidopsis lateral root initiation. Plant Cell 13:843-852.

Chandran, D., Inada, N., Hather, G., Kleindt, C. K., and Wildermuth, M. C. 2010. Laser microdissection of Arabidopsis cells at the powdery mildew infection site reveals site-specific processes and regulators. Proc. Natl. Acad. Sci. U.S.A. 107:460-465.

De Veylder, L., Larkin, J. C., and Schnittger, A. 2011. Molecular control and function of endoreplication in development and physiology. Trends Plant Sci. 16:624-634.

Devos, S., Laukens, K., Deckers, P., Van Der Straeten, D., Beeckman, T., Inzé, D., Van Onckelen, H., Witters, E., and Prinsen, E. 2006. A hormone and proteome approach to picturing the initial metabolic events during Plasmodiophora brassicae infection on Arabidopsis. Mol. Plant-Microbe Interact. 19:1431-1443.

Donald, E. C., Jaudzems, G., and Porter, I. J. 2008. Pathology of cortical invasion by Plasmodiophora brassicae in clubroot resistant and susceptible Brassica oleracea hosts. Plant Pathol. 57:201-209.

Evans, J., and Scholes, J. 1995. How does clubroot alter the regulation of carbon metabolism in its host? Asp. Appl. Biol. 42:125-132.

Fernandez, J., and Wilson, R. A. 2011. The sugar sensor, trehalose-6phosphate synthase (Tps1), regulates primary and secondary metabolism during infection by the rice blast fungus: Will Magnaporthe oryzae's "sweet tooth" become its "Achilles' heel"? Mycology 2:46-53.

Figueroa, C. M., and Lunn, J. E. 2016. A tale of two sugars: Trehalose 6phosphate and sucrose. Plant Physiol. 172:7-27.

Gravot, A., Grillet, L., Wagner, G., Jubault, M., Lariagon, C., Baron, C., Deleu, C., Delourme, R., Bouchereau, A., and Manzanares-Dauleux, M. J. 2011. Genetic and physiological analysis of the relationship between partial resistance to clubroot and tolerance to trehalose in Arabidopsis thaliana. New Phytol. 191:1083-1094.

Grsic-Rausch, S., Kobelt, P., Siemens, J. M., Bischoff, M., and Ludwig-Müller, J. 2000. Expression and localization of nitrilase during symptom development of the clubroot disease in Arabidopsis. Plant Physiol. 122:369-378.

Gustafsson, M., Liljeroth, E., Gunnarsson, M., and Lundborg, T. 1986. Effects of infection by Plasmodiophora brassicae on root anatomy of rape. J. Phytopathol. 117:144-151.

Irani, S., Trost, B., Waldner, M., Nayidu, N., Tu, J., Kusalik, A. J., Todd, C. D., Wei, Y., and Bonham-Smith, P. C. 2018. Transcriptome analysis of response to Plasmodiophora brassicae infection in the Arabidopsis shoot and root. BMC Genomics 19: Article 23.

Jahn, L., Mucha, S., Bergmann, S., Horn, C., Staswick, P., Steffens, B., Siemens, J., and Ludwig-Müller, J. 2013. The clubroot pathogen (Plasmodiophora brassicae) influences auxin signaling to regulate auxin homeostasis in Arabidopsis. Plants Basel 2:726-749.

Jubault, M., Lariagon, C., Taconnat, L., Renou, J.-P., Gravot, A., Delourme, R., and Manzanares-Dauleux, M. J. 2013. Partial resistance to clubroot in Arabidopsis is based on changes in the host primary metabolism and targeted cell division and expansion capacity. Funct. Integr. Genomics 13:191-205.

Jürgens, G. 2003. Growing up green: Cellular basis of plant development. Mech. Dev. 120:1395-1406.

Kageyama, K., and Asano, T. 2009. Life cycle of Plasmodiophora brassicae. J. Plant Growth Regul. 28:203. 
Keen, N. T., and Williams, P. H. 1969. Translocation of sugars into infected cabbage tissues during clubroot development. Plant Physiol. 44:748-754.

Lemarié, S., Robert-Seilaniantz, A., Lariagon, C., Lemoine, J., Marnet, N., Jubault, M., Manzanares-Dauleux, M. J., and Gravot, A. 2015. Both the jasmonic acid and the salicylic acid pathways contribute to resistance to the biotrophic clubroot agent Plasmodiophora brassicae in Arabidopsis. Plant Cell Physiol. 56:2158-2168.

Li, H., Li, X., Xuan, Y., Jiang, J., Wei, Y., and Piao, Z. 2018. Genome wide identification and expression profiling of SWEET genes family reveals its role during Plasmodiophora brassicae-induced formation of clubroot in Brassica rapa. Front. Plant Sci. 9:207.

Ludwig-Müller, J., Bendel, U., Thermann, P., Ruppel, M., Epstein, E., and Hilgenberg, W. 1993. Concentrations of indole-3-acetic acid in plants of tolerant and susceptible varieties of Chinese cabbage infected with Plasmodiophora brassicae Woron. New Phytol. 125:763-769.

Ludwig-Müller, J., Bennett, R. N., Kiddle, G., Ihmig, S., Ruppel, M., and Hilgenberg, W. 1999. The host range of Plasmodiophora brassicae and its relationship to endogenous glucosinolate content. New Phytol. 141:443-458.

Ludwig-Müller, J., Jülke, S., Geiß, K., Richter, F., Mithöfer, A., Šola, I., Rusak, G., Keenan, S., and Bulman, S. 2015. A novel methyltransferase from the intracellular pathogen Plasmodiophora brassicae methylates salicylic acid. Mol. Plant Pathol. 16:349-364.

Ludwig-Müller, J., Prinsen, E., Rolfe, S., and Scholes, J. 2009. Metabolism and plant hormone action during clubroot disease. J. Plant Growth Regul. 28:229-244.

Malinowski, R., Novák, O., Borhan, M. H., Spíchal, L., Strnad, M., and Rolfe, S. A. 2016. The role of cytokinins in clubroot disease. Eur. J. Plant Pathol. 145:543-557.

Malinowski, R., Smith, J. A., Fleming, A. J., Scholes, J. D., and Rolfe, S. A. 2012. Gall formation in clubroot-infected Arabidopsis results from an increase in existing meristematic activities of the host but is not essential for the completion of the pathogen life cycle. Plant J. 71:226-238.

Olszak, M., Truman, W., Stefanowicz, K., Sliwinska, E., Ito, M., Walerowski, P., Rolfe, S., and Malinowski, R. 2019. Transcriptional profiling identifies critical steps of cell cycle reprogramming necessary for Plasmodiophora brassicae-driven gall formation in Arabidopsis. Plant J. 97:715-729.

Pérez-López, E., Waldner, M., Hossain, M., Kusalik, A. J., Wei, Y., BonhamSmith, P. C., and Todd, C. D. 2018. Identification of Plasmodiophora brassicae effectors-A challenging goal. Virulence 9:1344-1353.

Prerostova, S., Dobrev, P. I., Konradyova, V., Knirsch, V., Gaudinova, A., Kramna, B., Kazda, J., Ludwig-Müller, J., and Vankova, R. 2018. Hormonal responses to Plasmodiophora brassicae infection in Brassica napus cultivars differing in their pathogen resistance. Int. J. Mol. Sci. 19:4024.

Ragni, L., Nieminen, K., Pacheco-Villalobos, D., Sibout, R., Schwechheimer, C., and Hardtke, C. S. 2011. Mobile gibberellin directly stimulates Arabidopsis hypocotyl xylem expansion. Plant Cell 23:1322-1336.

Roitsch, T., and Ehneß, R. 2000. Regulation of source/sink relations by cytokinins. Plant Growth Regul. 32:359-367.

Rolfe, S. A., Strelkov, S. E., Links, M. G., Clarke, W. E., Robinson, S. J., Djavaheri, M., Malinowski, R., Haddadi, P., Kagale, S., Parkin, I. A. P.,
Taheri, A., and Borhan, M. H. 2016. The compact genome of the plant pathogen Plasmodiophora brassicae is adapted to intracellular interactions with host Brassica spp. BMC Genomics 17: Article 272.

Schuller, A., Kehr, J., and Ludwig-Müller, J. 2014. Laser microdissection coupled to transcriptional profiling of Arabidopsis roots inoculated by Plasmodiophora brassicae indicates a role for brassinosteroids in clubroot formation. Plant Cell Physiol. 55:392-411.

Schwelm, A., Fogelqvist, J., Knaust, A., Jülke, S., Lilja, T., Bonilla-Rosso, G., Karlsson, M., Shevchenko, A., Dhandapani, V., Choi, S. R., Kim, H. G., Park, J. Y., Lim, Y. P., Ludwig-Müller, J., and Dixelius, C. 2015 The Plasmodiophora brassicae genome reveals insights in its life cycle and ancestry of chitin synthases. Sci. Rep. 5: Article 11153.

Siemens, J., González, M.-C., Wolf, S., Hofmann, C., Greiner, S., Du, Y. Rausch, T., Roitsch, T., and Ludwig-Müller, J. 2011. Extracellular invertase is involved in the regulation of clubroot disease in Arabidopsis thaliana. Mol. Plant Pathol. 12:247-262.

Slewinski, T. L., Zhang, C., and Turgeon, R. 2013. Structural and functional heterogeneity in phloem loading and transport. Front. Plant Sci. 4:244.

Taylor-Teeples, M., Lin, L., de Lucas, M., Turco, G., Toal, T. W., Gaudinier, A., Young, N. F., Trabucco, G. M., Veling, M. T., Lamothe, R., Handakumbura, P. P., Xiong, G., Wang, C., Corwin, J., Tsoukalas, A., Zhang, L., Ware, D., Pauly, M., Kliebenstein, D. J., Dehesh, K., Tagkopoulos, I., Breton, G., Pruneda-Paz, J. L., Ahnert, S. E., Kay, S. A., Hazen, S. P., and Brady, S. M. 2015. An Arabidopsis gene regulatory network for secondary cell wall synthesis. Nature 517:571-575.

Thompson, D. S. 2005. How do cell walls regulate plant growth? J. Exp. Bot. 56:2275-2285.

Verma, S. S., Rahman, M. H., Deyholos, M. K., Basu, U., and Kav, N. N. V. 2014. Differential expression of miRNAs in Brassica napus root following infection with Plasmodiophora brassicae. PLoS One 9:e86648.

Walerowski, P., Gündel, A., Yahaya, N., Truman, W., Sobczak, M., Olszak, M., Rolfe, S., Borisjuk, L., and Malinowski, R. 2018. Clubroot disease stimulates early steps of phloem differentiation and recruits SWEET sucrose transporters within developing galls. Plant Cell 30:3058-3073.

Walters, D. R., and McRoberts, N. 2006. Plants and biotrophs: A pivotal role for cytokinins? Trends Plant Sci. 11:581-586.

Wojtaszek, P. 2000. Genes and plant cell walls: A difficult relationship. Biol. Rev. Camb. Philos. Soc. 75:437-475.

Wolf, S., Mravec, J., Greiner, S., Mouille, G., and Höfte, H. 2012. Plant cell wall homeostasis is mediated by brassinosteroid feedback signaling. Curr. Biol. 22:1732-1737.

Yang, Y., Yue, R., Sun, T., Zhang, L., Chen, W., Zeng, H., Wang, H., and Shen, C. 2015. Genome-wide identification, expression analysis of GH3 family genes in Medicago truncatula under stress-related hormones and Sinorhizobium meliloti infection. Appl. Microbiol. Biotechnol. 99: 841-854.

Zhang, W., Wang, S., Yu, F., Tang, J., Yu, L., Wang, H., and Li, J. 2019. Genome-wide identification and expression profiling of sugar transporter protein (STP) family genes in cabbage (Brassica oleracea var. capitata L.) reveals their involvement in clubroot disease responses. Genes (Basel) 10:71 